\title{
Argumentative paragraphs identification with markers categories
}

\section{Identificación de párrafos argumentativos con categorías de marcadores}

\author{
GARCÍA-GORROSTIETA, Jesús Miguel*†, LÓPEZ-LÓPEZ, Aurelio, MADRID-MONTEVERDE, \\ José David and PONCE-MENDOZA, Ulises
}

Universidad de la Sierra, Moctezuma, Sonora, México.

ID 1 ${ }^{\text {st }}$ Author: Jesús Miguel, García-Gorrostieta / ORC ID: 0000-0001-6246-6795

ID $1^{\text {st }}$ Coauthor: Aurelio, López-López / ORC ID: 0000-0001-8832-3880

ID $2^{\text {nd }}$ Coauthor: José David Madrid-Monteverde / ORC ID: 0000-0001-5945-2165

ID $3^{\text {rd }}$ Coauthor: Ulises Ponce-Mendoza / ORC ID: 0000-0003-0719-7136

DOI: $10.35429 / J S E M .2020 .20 .7 .1 .6$

Received January 25, 2020; Accepted June 25, 2020

\begin{abstract}
The argumentation in theses is necessary to develop the ideas and convince the reader of the presented statements. However, among university students, there is a deficiency in their ability to argue, which is attended by teachers through the review process. In this article, we present a model for argumentative paragraph detection in sections such as the problem statement, justification, and conclusions. The classification task is performed using machine learning algorithms using five categories of argumentative markers. We present the sets of word patterns for each of the following categories: justification, explanation, deduction, refutation and conditional. Experiments were carried out to evaluate the argumentative paragraph identification reaching encouraging results.
\end{abstract}

Academic theses, Argument mining, Natural language processing

\begin{abstract}
Resumen
La argumentación en tesis es necesaria para desarrollar las ideas y convencer al lector de las afirmaciones presentadas. Sin embargo, entre los estudiantes de nivel superior existe una deficiencia en su habilidad de argumentar, la cual es subsanada por los profesores a través del proceso de revisión. En este artículo presentamos un modelo para la detección de párrafos argumentativos en secciones como el planteamiento del problema, justificación y conclusiones. La tarea de clasificación la realizamos empleando algoritmos de aprendizaje computacional utilizando cinco categorías de marcadores argumentativos. Presentamos los conjuntos de patrones de palabras para cada una de las siguientes categorías: justificación, explicación, deducción, refutación y condicional. Se realizaron experimentos para evaluar la identificación de párrafos argumentativos alcanzando resultados alentadores.
\end{abstract}

Tesis académicas, Minería de argumentos, Procesamiento del lenguaje natural

Citation: GARCÍA-GORROSTIETA, Jesús Miguel, LÓPEZ-LÓPEZ, Aurelio, MADRID-MONTEVERDE, José David and PONCE-MENDOZA, Ulises. La educación ambiental a través del aprendizaje colaborativo en línea. Argumentative paragraphs identification with markers categories. Journal of Systems and Educational Management. 2020. 7-20: 1-6.

\footnotetext{
*Correspondence to Author (Email: jgarcia@unisierra.edu.mx)
}

$\dagger$ Researcher contributing as first Author. 


\section{Introduction}

The argument today is all around us. Whether in electronic media such as forums or blogs, in which people write their opinions and present elements (evidence) so that these opinions are accepted as true, as well as in written media, such as: newspapers, magazines, legal texts, essays, scientific articles, thesis or research reports. From these means, particularly for scientific texts, it is necessary to offer reasoned arguments developed from clearly presented evidence that lead to a consistent conclusion (Lindsay, 2011).

In recent years, researchers have studied the task of automatic argument processing in a variety of fields such as law, with the aim of facilitating access to the jurisprudence that supports a case (Mochales and Moens, 2008, 2011; Wyner and Bench, Capon, 2007; Wyner et al., 2010). In political documents, automatic argument analysis has been studied to classify arguments into concepts and modes such as politics, fact, and value (Fierro et al., 2017). In scientific papers, particularly in biomedicine, automatic argument processing can be applied to more quickly identify arguments for or against a hypothesis under investigation (Green, 2015). In social networks, argumentation analysis is also used to identify the general position (for or against) of comments in a debate (Cabrio and Villata, 2012). There are also studies aimed at evaluating argumentation in trials (Persing and $\mathrm{Ng}$, 2015; Stab, 2017). Still, studies are lacking for larger and more complex academic papers, such as academic theses, particularly in Spanish.

In this article, we present a method for identifying argumentative paragraphs using computational learning techniques with a representation based on argumentative marker categories: justification, explanation, deduction, refutation, and conditional. To evaluate our method, a corpus of thesis arguments and endof-course projects were constructed with annotated argumentative paragraphs.

\section{State of the art}

The detection of argumentation in texts has been carried out at the level of paragraphs, sentences or clauses. Researchers like Moens et al. (2007), make the classification of argumentative and non-argumentative sentences in the Araucaria corpus, for which they represent sentences with characteristics such as combinations of word pairs, verbs and text statistics. Using a Bayes classifier they report $73.75 \%$ accuracy. Furthermore, Mochales and Moens (2011) use the ECHR corpus of legal texts with 47 annotated documents, where the clauses (subsentence) of the sentences are classified as argumentative or not using a maximum entropy classifier, and report an accuracy of $80 \%$ for that task. It is important to note that legal texts have a particular structure that allows lawyers to clearly identify the arguments.

On the other hand, the identification of argumentative paragraphs is investigated by Florou et al. (2013) who use 5 sets of argument categories (justification, explanation, deduction, refutation, and conditional) and characteristics based on the verb tense and tense. In this work, it is possible to identify text segments with argumentation, using a J48 decision tree classification algorithm, reporting an $\mathrm{F}$ measure of 0.764 .

Another approach for identifying argumentation in text segments is presented by Goudas et al. (2014), who build a corpus from 204 documents collected from social networks, which are annotated with their premises. They use structural, lexical, contextual, and grammatical features to represent each sentence. Using a logistic regression classifier they report an $\mathrm{F}$ measure of 0.77 .

\section{Argument structure}

The design of the argument structure is made using the argument diagramming technique with which it is possible to transfer the arguments from natural language to a structured representation, to analyze and evaluate them. This technique helps students formulate their arguments. This is done by identifying each premise and conclusion with a letter, which are associated with nodes of a graph. 
Subsequently, using directed arcs (arrows) it is possible to indicate the relationships between these components. A simple argument has only one premise that is used as the basis to support a conclusion (Walton, 2005).

\section{Argument example: [Today,} educational institutions have a greater number of computers with Internet.] / P1 [Therefore, more students have access to the Internet.] / C2

As seen in the example, the first sentence is a premise (in brackets / P1) that supports the conclusion in the second sentence (in brackets / C2). In the simple argument, a premise provides the foundation for supporting the veracity of the associated conclusion. Figureure 1 illustrates a simple argument structure where premise ' $A$ ' supports conclusion ' $\mathrm{B}$ '.

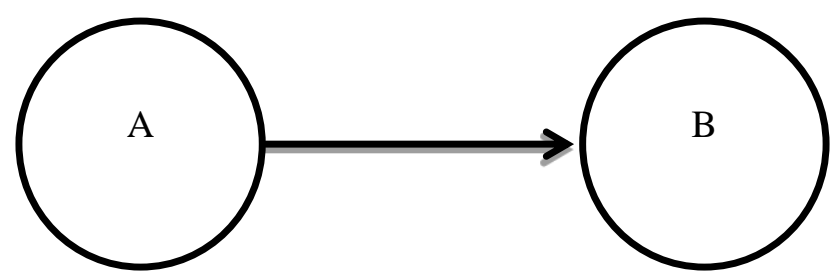

Figure 1 Diagrama de argumento sencillo Source: self made

As we can see from the argument example, the word "therefore" plays an essential role in identifying a possible conclusion; These word patterns are called argumentative markers and can help with detecting the elements of an argument. In Table 1 we present examples of argumentative markers proposed by Capaldi (1990) with which the identification of components is supported, however, the presence of an argumentative marker does not guarantee that there is an argument, as is the case of a conclusion without premises.

\begin{tabular}{|l|l|}
\hline Premises & $\begin{array}{l}\text { since, since, as, while, since, because, } \\
\text { seeing that, because, because }\end{array}$ \\
\hline Conclusions & $\begin{array}{l}\text { therefore, therefore, thus, consequently, } \\
\text { therefore, it follows that, as a result, we } \\
\text { come to the conclusion }\end{array}$ \\
\hline
\end{tabular}

Table 1 Argumentative markers Source: self made

\section{Corpus of Arguments}

The corpus was created using the Coltypi collection (Collection of theses and research proposals) (González-López and López-López, 2015), which has 468 theses and research proposals from the area of computer science and information technology, written in Spanish. The texts belong to the undergraduate (undergraduate and higher university technical) and postgraduate (master and doctorate) levels. In particular, our study focuses on the Problem Statement, Justification and Conclusions sections, since these are considered highly argumentative (López Ferrero and García Negroni, 2003).

The corpus was built with 444 sections with at least two annotations per section. The annotation team consisted of seven linguisticsrelated field annotators who worked on different subsets of the corpus. This was a challenging task for scorers due to the variety of complex computing concepts discussed in the theses.

The corpus documents show systems analysis and development for companies, government and universities. They cover topics such as the use of smart agents, mobile systems, automation, voice analysis, simulations, robotics, wireless networks, VoIP telephony, software architecture, computer learning, information retrieval systems, image recognition, analysis of voice, virtual reality, web developments, home automation systems, etc.

A total of 1,973 paragraphs were noted. A level of agreement between annotators is observed for the identification of argumentative paragraphs of Cohen kappa (Cohen, 1960) of 0.399, which places it at a 'fair' level of agreement. For the generation of the corpus for the identification of argumentative paragraphs, only the paragraphs where the two annotators agreed were selected and at least two argumentative components were identified. This restriction reduces the number of paragraphs to 1,174 where we find that 830 are argumentative with a proportion of $70.7 \%$ and with 344 paragraphs without argument. 


\section{Argumentative Marker Categories}

Argumentative markers help in the identification of components of an argument and with it the detection of argumentative paragraphs. The argumentative marker categories correspond to five sets of word patterns (argumentative markers), used to obtain the frequency of each of the following categories: justification, explanation, deduction, refutation, and conditional. Sets of patterns were created based on the review of different sources of argumentative markers in Spanish (Briz et al., 2008; Rodríguez, 2009; Sánchez Avendaño, 2005). Some examples of these patterns are 'since-for', for the justification category, this pattern is related to the argumentative component of premise; or 'therefore', for the deduction category, which indicates a conclusion. The slogans of the word patterns were used in order to capture a greater number of expressions. From the corpus we obtained 43 paragraphs with argumentation without argumentative markers and 787 paragraphs with argumentation with indicators. In addition, 29 non-arguing paragraphs without bookmarks and 315 non-arguing paragraphs with bookmarks were found. This indicates that $94.8 \%$ of the paragraphs with argumentation have bookmarks, however, $91.6 \%$ of the paragraphs without argument also have bookmarks, which indicates that the bookmarks are found both in paragraphs with argumentation and without argumentation. Below are the pattern lists of the constructed categories.

Category of justification: because of, to the end and to the end, to the end and to the end, after all, how, how to show, how to be indicated by, with say you, give that, according to, in fact , owe to, owe to, after all, the above because, the motive to be, the reason to be, the reason to be that, while, in view of the fact that, thanks to, not in vain, put to be a consequence of, for the sake of, therefore, for all of this, because, since, because, because it can be deduced from, it can be derived from, it will follow from, it will be, see that, since.

Category of explanation: because, in the end, thus, in another way, must, to say in another way, the reason to be, specifically, definitively, in another word, in particular, the reason to be, reason to that, put, put by case, for example, for that reason, for that reason, for this reason, for this reason, reason that, one example, one put.
Deduction category: as a result of, to the end and the end, before the above, so, so, so, as a conclusion, as a consequence, as a result, conclude that, conclusion, consequently, consequently, correspondingly, the former, hence, in this way, in such a way, in such a way, in such a way, to deduce that to demonstrate that, which to point to the conclusion that, which to imply that, which to show that, which allow to infer that, which to prove that, which to mean that, in conclusion, consequently, definitively, finally, in summary, in summarizing account, in itself, in synthesis, in sum, in such a case, then, to establish that, finally, imply that, infer that, reach it, reach the conclusion, to, to conclude, to finish, to be able to infer that, therefore, therefore, therefore, therefore, therefore, for this reason, therefore, finally, to prove that, that, to summarize, to detach, detach from, I know what to follow, why.

Category of refutation: on the contrary, unless, despite, despite everything, now, rather, even so, although, well to the contrary, anyway, anyway, after all, however, in change, that yes, more, even more, rather, quite the contrary, however, does not seem, but, however, despite, on the contrary, on the contrary, because, although, however, but, except that.

Conditional category: according, provided, provided that, unless, with that, suppose that, although, if, in case of, if and only if.

Using the argumentative marker categories it is possible to obtain a vector representation of the text based on the pattern count of each category. The representation of the argument example presented in the argument structure section generates the vector [jus: 0 , exp: 0, ded: 1, ref: 0 , with: 0 ] in which we observe that only a single pattern is found in the deduction category, this being the pattern of "therefore".

\section{Experimental results}

The task of detecting argumentative paragraphs was approached as a binary classification to detect if a certain paragraph contains argumentation. The experiments used a 10-fold layered cross-validation using the Scikit-learn Toolkit (Pedregosa et al., 2011). The Weka machine learning tool was used to perform the classification (Hall et al., 2009). 
The classifiers used were Support Vector Machine (SVM) (Stab and Gurevych, 2014), Naive Bayes (NB) (Moens et al., 2007), Decision Tree (DT) (Florou et al., 2013) and Random Forest (RF) (Carstens and Toni, 2015) since, previously, they have been used in argument mining.

\begin{tabular}{|l|r|r|r|r|}
\hline \multicolumn{2}{|c}{} & \multicolumn{3}{c}{ Class f1 } \\
\hline Accuracy & F1 macro & with arg & \multicolumn{1}{l|}{$\begin{array}{l}\text { without } \\
\text { arg }\end{array}$} \\
\hline SVM & $70.7 \%$ & 0.414 & 0.828 & 0.000 \\
\hline RF & $72.9 \%$ & 0.666 & 0.811 & 0.521 \\
\hline NB & $65.4 \%$ & 0.642 & 0.709 & 0.574 \\
\hline DT & $76.6 \%$ & 0.695 & 0.842 & 0.548 \\
\hline
\end{tabular}

Table 2 Detection results of argumentative paragraphs using marker categories. The Support Vector Machine classification algorithm is indicated with SVM, likewise RF for Random Forest, NB for Naive Bayes and DT for Decision Tree

Source: self made

The representation was constructed by calculating the frequency of the argumentative categories for each paragraph in the corpus. Subsequently, classifiers were trained with the training data set and evaluated using the test set. Table 2 shows the accuracy and F1 measurements achieved by the analyzed classifiers. We look at the DT classifier, which achieves the best accuracy with $76.6 \%$, which indicates that it is wrong only $23.4 \%$ of the time. In addition, we observe that it manages to better detect paragraphs with argumentation with a measure F1 for the class "with arg" of 0.842. On the other hand, we observe that the SVM classifier achieves an accuracy of $70.7 \%$ but with a macro F1 of 0.414 , in the detection of paragraphs without argumentation it reports an F1 measure for the class "without arg" of 0 (zero), with which highlights the importance of considering metrics such as the F1 measure in particular for unbalanced sets.

\section{Conclusions}

In this article we present a model for detecting argumentative paragraphs using argumentative marker categories. Categories of argumentative markers constructed to generate a vector representation that allow the classification task were presented. It was observed that, in the academic theses, particularly for the sections of the problem statement, justification and conclusions, they are mostly paragraphs with argumentation.
Based on the results, the best accuracy and F-measure observed in our experiments to identify paragraphs with arguments using argumentative marker categories was achieved using the decision tree (DT) classification algorithm. In future works it is planned to implement a system that uses the developed model to present to the student the number of argumentative paragraphs detected in his writing.

\section{References}

Briz, A., Pons, S., y Portolés, J. (2008). Diccionario de partículas discursivas del español. In El diccionario como puente entre las lenguas y culturas del mundo. Actas del II Congreso Internacional de Lexicografía Hispánica. Alicante, Biblioteca Virtual Cervantes, pages 217-227. Alicante: Biblioteca Virtual Miguel de Cervantes.

Cabrio, E. y Villata, S. (2012). Combining textual entailment and argumentation theory for sup- porting online debates interactions. In Proceedings of the 50th Annual Meeting of the Association for Computational Linguistics: Short Papers - Volume 2, ACL '12, pages 208212. Association for Computational Linguistics.

Capaldi, N. (1990). Cómo ganar una discusión. Gedisa.

Carstens, L. y Toni, F. (2015). Towards relation based argumentation mining. In Procs. of the 2nd Workshop on Argumentation Mining, pages 29-34, Denver, CO. ACL.

Chris Reed, Raquel Mochales Palau, G. R. y Moens, M.-F. (2008). Language resources for studying argument. In Nicole1a Calzolari (Conference Chair), Khalid Choukri, B. M. J. M. J. O. S. P. D. T., editor, Proceedings of the Sixth International Conference on Language Resources and Evaluation (LREC'08), pages 2613-2618, Marrakech, Morocco. European Language Resources Association (ELRA).

Cohen, J. (1960). A coefficient of agreement for nominal scales. Educational and Psychosocial Measurement, 20(1):37-46.

Fierro, C., Fuentes, C., Pérez, J., y Quezada, M. (2017). 200k+ crowdsourced political arguments for a new chilean constitution. In Proceedings of the 4th Workshop on Argument 
Mining, pages 1-10, Copenhagen, Denmark. Association for Computational Linguistics.

Florou, E., Konstantopoulos, S., Koukourikos, A., y Karampiperis, P. (2013). Argument extraction for supporting public policy formulation. In Procs. of the 7th Workshop on Language Technology for Cultural Heritage, Social Sciences, and Humanities, pages 49-54.

González-López, S. y López-López, A. (2015). Colección de tesis y propuesta de investigación en tics: un recurso para su análisis y estudio. In XIII Congreso Nacional de Investigación Educativa, pages 1-15.

Goudas, T., Louizos, C., Petasis, G., y Karkaletsis, V. (2014). Argument extraction from news, blogs, and social media. In Hellenic Conference on Artificial Intelligence, pages 287-299. Springer.

Green, N. (2015). Identifying argumentation schemes in genetics research articles. In Proceedings of the 2nd Workshop on Argumentation Mining, pages 12-21. Association for Computational Linguistics.

Hall, M., Frank, E., Holmes, G., Pfahringer, B., Reutemann, P., y Wilen, I. H. (2009). The weka data mining sokware: an update. ACM SIGKDD explorations newsleMer, 11(1):10-18.

Lindsay, D. (2011). Scientific Writing. CSIRO Publishing.

López Ferrero, C. y García Negroni, M. (2003). La argumentación en los géneros académicos. In Actas del Congreso Internacional La Argumentación, pages 1121-1129. Universidad de Buenos Aires, Buenos Aires.

Mochales, R. y Moens, M.-F. (2011). Argumentation mining. Artificial Intelligence and Law, 19(1):1-22.

Moens, M.-F., Boiy, E., Palau, R. M., y Reed, C. (2007). Automatic detection of arguments in legal texts. In Procs. of the 11th International Conference on Artificial Intelligence and Law, pages 225-230. ACM.

Pedregosa, F., Varoquaux, G., Gramfort, A., Michel, V., Thirion, B., Grisel, O., Blondel, M., Prelen-hofer, P., Weiss, R., Dubourg, V., Vanderplas, J., Passos, A., Cournapeau, D.,
Brucher, M., Perrot, M., y Duchesnay, E. (2011). Scikit-learn: Machine learning in python. Journal of Machine Learning Research, 12(Oct):2825-2830.

Persing, I. y Ng, V. (2015). Modeling argument strength in student essays. In Proceedings of the 53rd Annual Meeting of the Association for Computational Linguistics and the 7th International Joint Conference on Natural Language Processing, pages 543-552, Beijing, China. Association for Computational Linguistics.

Rodríguez, C. F. (2009). Diccionario de conectores y operadores del español. Arco/Libros.

Sánchez Avendaño, C. (2005). Los conectores discursivos: su empleo en redacciones de estudiantes universitarios costarricenses. Revista de Filología y Lingüística de la Universidad de Costa Rica, 31(2):169-199.

Stab, C. y Gurevych, I. (2014). Identifying argumentative discourse structures in persuasive es- says. In Procs. of the Conference on Empirical Methods in Natural Language Processing, pages 46-56. ACL.

Stab, C. y Gurevych, I. (2017). Parsing argumentation structures in persuasive essays. Computational Linguistics, 43(3):619-659.

Walton, D. (2005). Fundamentals of critical argumentation. Cambridge University Press.

Wyner, A. y Bench-Capon, T. (2007). Towards an extensible argumentation system. In Proceedings of the Ninth European Conferences on Symbolic and Quantitative Approaches to Reasoning with Uncertainty, pages 283-294. Springer.

Wyner, A., Mochales-Palau, R., Moens, M.-F., y Milward, D. (2010). Approaches to text mining arguments from legal cases. In Semantic Processing of Legal Texts: Where the Language of Law Meets the Law of Language, pages 6079. Springer. 